\title{
Radiation hardening techniques for rare-earth based optical fibers and amplifiers
}

\author{
Sylvain Girard ${ }^{* a}$, Marilena Vivona ${ }^{\mathrm{b}, \mathrm{c}, \mathrm{d}}$, Luciano Mescia ${ }^{\mathrm{e}}$, Arnaud Laurent ${ }^{\mathrm{b}}$, Youcef Ouerdane ${ }^{\mathrm{c}}$, \\ Claude Marcandella ${ }^{\mathrm{a}}$, F. Prudenzano ${ }^{\mathrm{f}}$, Aziz Boukenter ${ }^{\mathrm{c}}$, Thierry Robin ${ }^{\mathrm{b}}$, Benoît Cadier ${ }^{\mathrm{b}}$, \\ Emmanuel Pinsard ${ }^{\mathrm{b}}$, Marco Cannas ${ }^{\mathrm{d}}$, Roberto Boscaino ${ }^{\mathrm{d}}$ \\ ${ }^{a}$ CEA, DAM, DIF, F-91297 Arpajon, France \\ ${ }^{b}$ iXFiber, Rue Paul Sabatier F-22300 Lannion, France \\ ${ }^{c}$ Lab. Hubert Curien, UMR CNRS 5516, Université de Saint-Etienne, F-42000 Saint-Etienne, France \\ ${ }^{\mathrm{d} U n i v e r s i t a ̀ ~ d i ~ P a l e r m o, ~ I-90123 ~ P a l e r m o, ~ I t a l y ~}$ \\ ${ }^{\text {e }}$ Dipartimento di Elettrotecnica ed Elettronica, Politecnico di Bari, I-70125 Bari, Italy \\ ${ }^{\text {f } D i p a r t i m e n t o ~ d i ~ I n g e g n e r i a ~ d e l l ' A m b i e n t e ~ e ~ p e r ~ l o ~ S v i l u p p o ~ S o s t e n i b i l e, ~ P o l i t e c n i c o ~ d i ~ B a r i, ~ I-~}$ \\ 70125 Bari, Italy
}

\begin{abstract}
$\mathrm{Er} / \mathrm{Yb}$ doped fibers and amplifiers have been shown to be very radiation sensitive, limiting their integration in space. We present an approach including successive hardening techniques to enhance their radiation tolerance. The efficiency of our approach is demonstrated by comparing the radiation responses of optical amplifiers made with same lengths of different rare-earth doped fibers and exposed to gamma-rays. Previous studies indicated that such amplifiers suffered significant degradation for doses exceeding $10 \mathrm{krad}$. Applying our techniques significantly enhances the amplifier radiation resistance, resulting in a very limited degradation up to $50 \mathrm{krad}$. Our optimization techniques concern the fiber composition, some possible pre-treatments and the interest of simulation tools used to harden by design the amplifiers. We showed that adding cerium inside the fiber phosphosilicate-based core strongly decreases the fiber radiation sensitivity compared to the standard fiber. For both fibers, a pre-treatment with hydrogen permits to enhance again the fiber resistance. Furthermore, simulations tools can also be used to improve the tolerance of the fiber amplifier by helping identifying the best amplifier configuration for operation in the radiative environment.
\end{abstract}

Keywords: radiation effects, optical fibers, erbium, ytterbium, amplifiers

\section{INTRODUCTION}

The incorporation of Rare-Earth (RE), like Erbium (Er) and/or Ytterbium (Yb) doped optical fibers in radiative environments is now widely studied as these components are a key element of fiber-based systems like amplifiers or lasers with high power capabilities. This type of optical fiber was also shown to be the most sensitive part of these systems to radiation effects [1,2]. As a consequence and despite the short length used for space applications, the study of their vulnerability to the harsh environment associated with space missions remains crucial [3]. Most of the previous studies have been devoted to the characterization of their radiation response in a passive configuration (with no amplification) with setups comparable to those used for the characterization of passive optical fibers [1-5]. For most of the RE-doped fibers, such as those containing aluminum or phosphorus as codopants of the core silica-based matrix, the

**sylvain.girard@cea.fr; phone 33 169264000; fax 33 169267116;

Free-Space Laser Communication Technologies XXIV, edited by Hamid Hemmati, Don M. Boroson, Proc. of SPIE Vol. 8246, 82460Y · (C) 2012 SPIE · CCC code: 0277-786X/12/\$18 · doi: 10.1117/12.907238 
point defects at the origin of the fiber degradation, through the radiation-induced attenuation phenomenon, seem related to the glass matrix chosen for the active ion incorporation $[1,6]$.

Other studies characterized the response of actively-pumped Er-doped optical fibers [7-9]. Fewer studies have been carried out on the $\mathrm{Er} / \mathrm{Yb}$ doped amplifiers. M. Alam et al. [10] showed important degradation of an $\mathrm{Yb} / \mathrm{Er}$ amplifier output power with cumulated dose; they reported a complete darkening of a $\mathrm{Yb} / \mathrm{Er}$ amplifier (extinction of the amplified signal) after an irradiation dose of $20 \mathrm{krad}$ (at a dose rate of $20 \mathrm{rad} / \mathrm{s}$ ) or $40 \mathrm{krad}$ (dose rate of $10 \mathrm{rad} / \mathrm{s}$ ). More recently, J. $\mathrm{Ma}$ et al. [11] also reported the decrease of a $\mathrm{Yb} / \mathrm{Er}$ amplifier gain from $25 \mathrm{~dB}$ to $0 \mathrm{~dB}$ after irradiation at a dose of 50 $\mathrm{krad}(40 \mathrm{rad} / \mathrm{s})$. These previous studies demonstrate the importance of designing new types of $\mathrm{Yb} / \mathrm{Er}$ optical fibers with better radiation tolerance. We previously presented [12] the radiation responses of two differently doped $\mathrm{Er} / \mathrm{Yb}$ doped optical fibers. One of these fibers is radiation hardened thanks to a special composition of its fiber core. We demonstrated the high radiation tolerance of an amplifier based on this Cerium-codoped fiber through characterization of its behavior under gamma radiations. In this paper, we showed that the radiation resistance of these two fibers and associated amplifiers can be further improved by appropriate pre-treatments like pre-loading of the fiber with hydrogen or by acting on the amplifier configuration to reduce by hardening by system the relative influence of radiation on REdoped fibers on their radiation response.

\section{EXPERIMENTAL PROCEDURE}

\subsection{Tested optical fibers}

In this paper, we present results obtained on a set of four new prototype RE-doped fibers compositions including both $\mathrm{Er}^{3+}$ and/or $\mathrm{Yb}^{3+}$ ions in their cores. These fibers have been developed by Ixfiber SAS [12]. The two investigated fiber structures were designed with an octagonal double-clad (DC) that is used to facilitate the high power laser pumping of the RE ions located in the fiber cores. This double clad is made of comparable pure-silica glass for each optical fiber. Both fibers have a core doped with the two rare-earth ions $\mathrm{Er}^{3+}$ and $\mathrm{Yb}^{3+}$ as well as a codoping of the glass matrix with phosphorus. For such fibers, phosphorus has been shown to be able to increase the refractive index of the silica glass and to facilitate the energy transfer from the $\mathrm{Yb}^{3+}$ to the $\mathrm{Er}^{3+}$ ions thanks to the phonons associated to the phosphorus-oxygen double bonds $(\mathrm{P}=\mathrm{O})$. Previous tests reveal that the presence of the phosphorus, if it increases the amplification efficiency of the glass before irradiation, is also responsible for the main part of the infrared radiation-induced attenuation (RIA) when they are submitted to different types of irradiations (gamma ray or protons tests). The $\mathrm{P}_{1}$ points defects related to the phosphorus that are responsible for the degradation have been identified; their structure is close to the SiE' center in pure silica. We also showed that the concentration of these defects can be affected by the presence of other codopants like aluminum. We tentatively explained this response by a competition phenomenon for the trapping of the charges released by irradiation between the different color centers associated to these codopants. This phenomenon was used in this work as we added cerium ions in the core of one of the two studied fibers, in order to compete with $\mathrm{P}_{1}$ centers and then improve the radiation tolerance [13]. Therefore, the two tested fibers $\# 1$ and $\# 2$ have globally the same active core (phosphosilicate glass doped with erbium and ytterbium rare-earth ions) except that fiber $\# 2$ also contains cerium in its core. An important point is that the spectroscopic properties of the $\mathrm{Er}^{3+}$ and $\mathrm{Yb}^{3+}$ rare-earth ions are poorly affected by the incorporation of the cerium inside the core, as shown in [12].

Samples of these two fibers were hydrogen-loaded during $48 \mathrm{~h}$ at the following conditions: 192 bars and $80^{\circ} \mathrm{C}$. The resulting pre-treated fibers are noted as $\# 1 \mathrm{H}$ and $\# 2 \mathrm{H}$. The fibers are coated with acrylate that did not allow keeping the hydrogen confined inside the fiber for a long time as metal-coated fibers do [14]. The fiber tests were done several days after irradiation meaning that most of the hydrogen should have diffused out the fiber at the time of the gamma irradiation.

\subsection{Tested optical amplifiers}

Based on the two prototype active fibers, two amplifiers (AMP\#1 and AMP\#2) have been designed by Ixfiber with $12 \mathrm{~m}$ length of active fibers. As expected, despite their difference (presence of Cerium in Fiber $\# 2$ core), we were able to 
obtain comparable performance for these two amplifiers. Figures $1 \mathrm{a}$ and $1 \mathrm{~b}$ present the output power dependence at $1545 \mathrm{~nm}$ of the two amplifiers on the pump current. As it can be noticed, for both fibers, we were able to amplify a $10 \mathrm{~mW}$ signal at $1545 \mathrm{~nm}$ to nearly $800 \mathrm{~mW}$ by pumping the $\mathrm{Yb}^{3+}$ ions at $915 \mathrm{~nm}$.

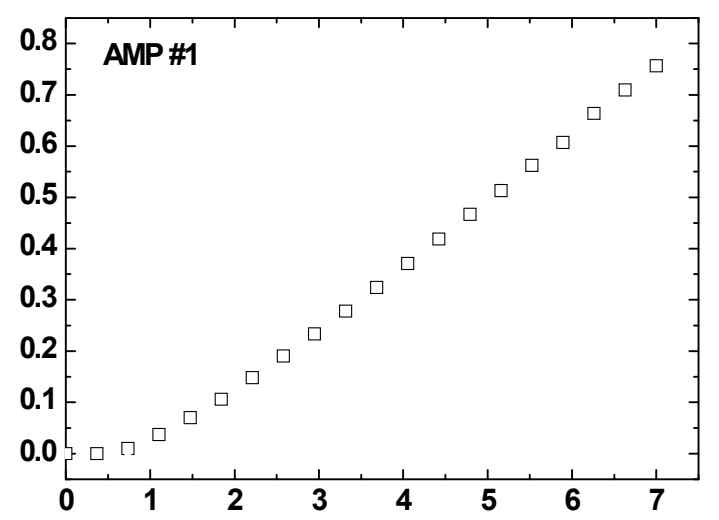

(a)

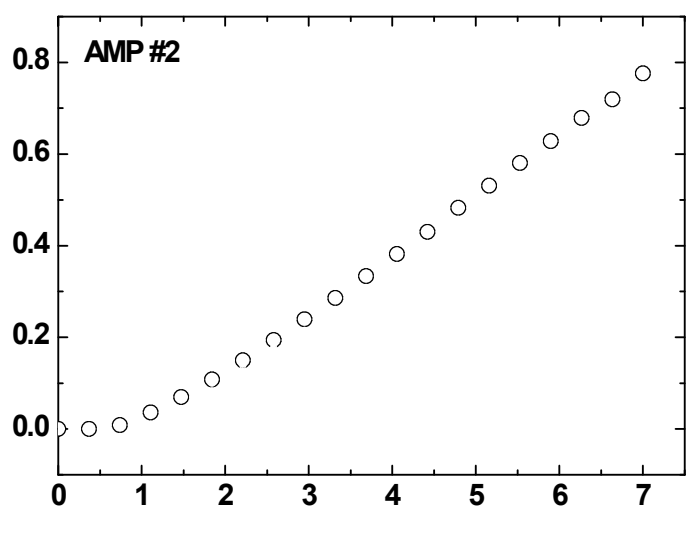

(b)

Figure 1. Dependence of the amplifier output power versus the pump current for (a) the amplifier AMP\#1 based on fiber \#1

(YbErP) and for (b) the amplifier AMP\#2 based on fiber \#2 (YbErPCe)

Then, the two tested amplifiers exhibited, before irradiation, a $19 \mathrm{~dB}$ gain (including a $1.4 \mathrm{~dB}$ attenuation of output section) with a $10 \mathrm{dBm}$ input power. It is important to notice that we limited the output power to $1 \mathrm{~W}$ at $1545 \mathrm{~nm}$ for these experiments. However, this amplifier design can easily extract up to $10 \mathrm{~W}$ with sufficient pump and input power available.

Amplifiers made with the pre-treated optical fibers have close characteristics in terms of performance. A slight decrease of the output power at a given input current is observed for these amplifiers done with the \#1H and \#2H fibers. These amplifiers are noted AMP\#1H and AMP\#2H, respectively.

\subsection{Irradiation tests}

We used a ${ }^{60} \mathrm{Co}$ source to characterize the radiation sensitivity of our devices at low dose rate $(\sim 0.3 \mathrm{rad} / \mathrm{s})$ and cumulative doses of up to $50 \mathrm{krad}$. All these experiments have been conducted at room temperature $\left(\sim 18^{\circ} \mathrm{C}\right)$.

Figure 2 illustrates the experimental setup used for the online characterization of the degradation of a fiber-based $\mathrm{Yb} / \mathrm{Er}-$ doped amplifier. Only the active fiber $(12 \mathrm{~m}$ length) is exposed to the $\gamma$-rays. All other equipments like diodes, lasers and detectors remain in a radiation-free instrumentation zone for this set of experiments. 


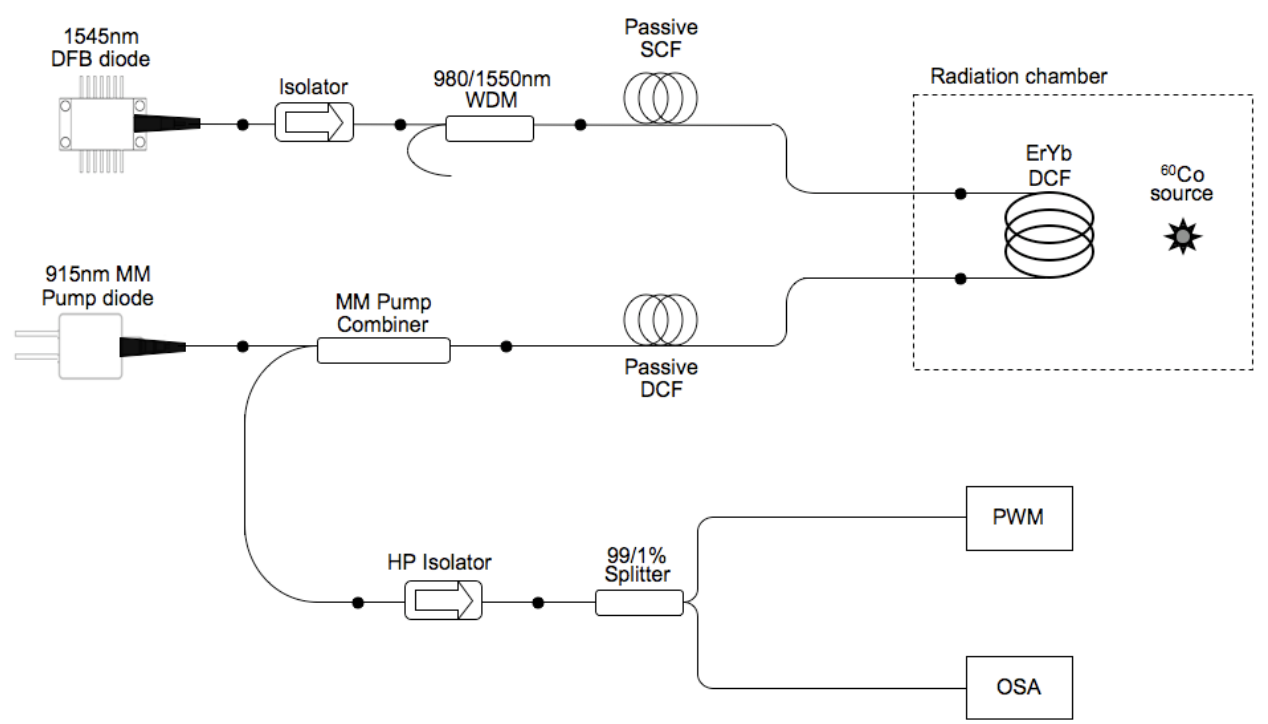

Fig.2. Experimental setup used for the characterization of RE-doped fibers in their active configuration (OSA=Optical Spectrum Analyzer, $\mathrm{PWM}=$ Power Meter, $\mathrm{DCF}=$ Double Clad Fibers, $\mathrm{SCF}=$ Single Clad Fiber)

We used a $915 \mathrm{~nm}$ multimode pump diode to excite the rare-earth ions in a contrapropagative scheme. The signal from a $1545 \mathrm{~nm}$ DFB diode is then amplified from about $10 \mathrm{~mW}$ to nearly $1 \mathrm{~W}$ depending on the injected pump power. By using this technique, we can characterize the changes in the amplifier output power at $1545 \mathrm{~nm}$ thanks to a photodiode and at the same time, record the changes in the spectral properties of the amplified signal with an optical spectrum analyzer (OSA).

\subsection{Amplifier simulation tools}

We used existing models that reproduce the mechanisms leading to the infrared signal amplification in RE-doped optical fibers. These models are mainly used to optimize the performance of the amplifiers in terms of gain and noise figure without considering the radiation effects on their optical performances. To optimize amplifiers, researchers used these tools to identify the optimal amplifier design parameters (active fiber length, pumping scheme, RE concentration, refractive-index, geometrical parameters of the fiber transversal section) that maximize the amplification around 1550 $\mathrm{nm}$. However, as the characteristics of the fiber will change with radiations, it can be clearly seen that such calculation tools, if they include radiation effects, may also be used to enhance the amplifier performance not only before irradiation but also, for example, for a space mission by a more judicious choice of these "optimal" parameters [15]. Furthermore, such an optimization of the amplifier can only be performed through simulations as it will require a too large number of samples and radiation experiments to identify the optimal system at reasonable costs.

\section{EXPERIMENTAL RESULTS /DISCUSSION}

Fig. 4 presents the dose dependence of the calculated radiation-induced attenuation (RIA) measured for the $1545 \mathrm{~nm}$ output powers of the four amplifiers with the gamma dose. These measurements were obtained with a pump current of $7 \mathrm{~A}$ and the following formula:

$\operatorname{RIA}(\mathrm{dB} / \mathrm{m})=-10 / \mathrm{L} \times \log \left(\mathrm{P}(\mathrm{D}) / \mathrm{P}_{0}\right)$

Where $\mathrm{L}$ is the fiber length used to design the amplifiers and was equal to $12 \mathrm{~m}$ for all tested amplifiers. $\mathrm{P}(\mathrm{D})$ is the measured output power at a considered dose $\mathrm{D}$ and $\mathrm{P}_{0}$ is the output power measured for the amplifiers before irradiation. 


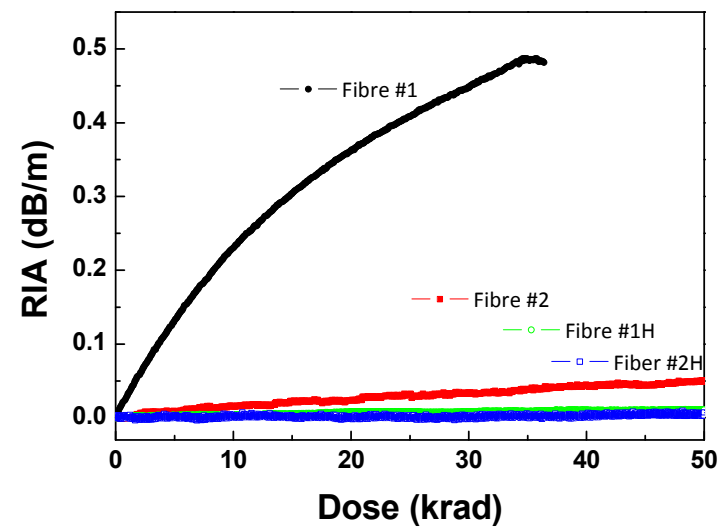

Fig.3. Dependence of amplifier output power at $1545 \mathrm{~nm}$ versus the deposited dose (dose rate of $0.3 \mathrm{rad} / \mathrm{s}$ ).

Our results showed that irradiation at only a few tenths of krad of the active fiber induces a strong degradation of the amplifier AMP\#1 output power $(\sim 80 \%$ at $40 \mathrm{krad}$, corresponding to $0.5 \mathrm{~dB} / \mathrm{m})$ as illustrated in Figure 3 . For this amplifier, the output power continuously decreases in the whole range of tested doses. However, for amplifier AMP\#2 designed with Ce codoped fiber $\# 2$, only a low degradation level is observed: less than $20 \%$ of the amplifier output power is lost after a $40 \mathrm{krad}$ dose. We remark that this degradation level is quickly observed after a dose of $\sim 5 \mathrm{krad}$ and remains stable at higher dose. Results at higher dose levels (up to $90 \mathrm{krad}$ ) revealed an output power decrease of less than $\sim 30 \%$ for this amplifier. For the two amplifiers designed with the $\mathrm{H}_{2}$-loaded fibers, extremely low losses are measured and the amplifiers can be considered as unaffected by radiations. The comparison between our results and those from literature $[10,11]$ confirm the excellent radiation tolerance of the tested optical fibers

We also used simulation tools to evaluate the hardening possibility offered by the optimization of the optical amplifier for use in a given harsh environment. Figure 4 illustrate the output power at $1545 \mathrm{~nm}$ versus the length of fiber used to design the amplifier before irradiation and considering different doses from 7 to $70 \mathrm{krad}$. For these calculations, radiation effects have been considered taking into account the changes induced by radiation around the pump and signal wavelengths.

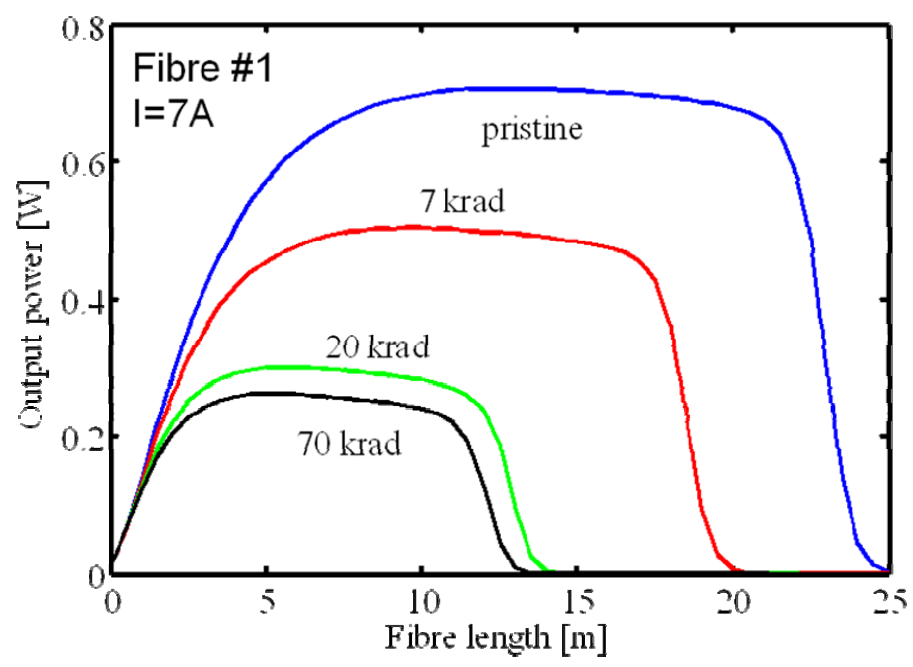

Fig.4. Simulation of the dependence of amplifier output power at $1545 \mathrm{~nm}$ versus the fiber length at different doses.

From this comparison, it clearly appears that the more favorable length of fiber for the maximal amplification will change with the deposited dose. When the dose increases, the RIA will increase and compete with the absorption of the 
pump by the rare-earth ions. In case, the RIA is so high that it results in the total absorption of the pump before the end of the used fiber length, then the gain of the amplifier will abruptly decrease. This is quickly observe for a length of $15 \mathrm{~m}$ and will be the case, for a $12 \mathrm{~m}$ length, if dose exceeds $70 \mathrm{krad}$ from our simulation results

\section{CONCLUSION}

We have developed a new radiation-tolerant $\mathrm{Er} / \mathrm{Yb}$ doped double clad optical fiber that has been used to design an amplifier at $1545 \mathrm{~nm}$ (gain of $20 \mathrm{~dB}$ for an input power of $10 \mathrm{dBm}$ ). Our irradiation tests confirm that this amplifier is less affected by radiations than the one built with a classical phosphosilicate $\mathrm{Er} / \mathrm{Yb}$ doped optical fiber. The degradation of its output power remains below $20 \%$ after an irradiation dose level of $50 \mathrm{krad}$ whereas it decreases up to about $80 \%$ after $40 \mathrm{krad}$ for the second one. Pre-treatment of the fibers with hydrogen allows to strongly reduce the amplifier radiation sensitivity. The exact influence of hydrogen still needs to be investigated in the future. At this time, most of the optimization of the radiative performance of our amplifier has been done by improving the radiation response of active fiber. In the future, simulations tools that are under development will be routinely used to enhance even more the behavior of our amplifiers by optimizing the amplifier parameters such as fiber length, propagative scheme ...

\section{REFERENCES}

[1] S. Girard, B. Tortech, E. Regnier; M. Van Uffelen; A. Gusarov, A.; Y. Ouerdane, J. Baggio, P. Paillet, V. Ferlet-Cavrois, A. Boukenter, J-P. Meunier, F. Berghmans, J.R. Schwank, M.R. Shaneyfelt, J.A. Felix, E.W. Blackmore, H. Thienpont "Proton- and gamma-induced effects on erbium- doped optical fibers", IEEE Transactions on Nuclear Sciences, vol. 54, n6, pp. 2426-2434, 2007.

[2] G.M. Williams, M.A. Putnam, C.G. Askins, M.E. Gingerich, E.J. Friebele, "Radiation effects in erbium-doped optical fibres", IEE Electronic Letters 28, pp. 1816-1818, 1992.

[3] M. Ott, "Radiation Effects expected for Fiber Laser/Amplifier and Rare-Earth doped Optical Fibers, NASA GSFC, Parts, Packaging and Assembly Technologies Office Survey Report, 2004.

[4] B.P. Fox, K. Simmons-Potter, W.J. Thomes, D.A.V. Kliner, "Gamma-Radiation-Induced Photodarkening in Unpumped Optical Fibers Doped With Rare-Earth Constituents", IEEE Transactions on Nuclear Sciences, vol. $57, n^{\circ} 3$, pp. $1618-1625,2010$.

[5] B.P. Fox et al., "Temperature and dose-rate effects in gamma irradiated rare-earth doped fibers" SPIE 7095, 70950B, 2008.

[6] S. Girard, Y. Ouerdane, B. Tortech, C. Marcandella, T. Robin, B. Cadier, J. Baggio, P. Paillet, V. FerletCavrois, A. Boukenter, J-P. Meunier, J. R. Schwank, M.R. Shaneyfelt, P.E. Dodd, E.W. Blackmore "Radiation Effects on Ytterbium- and Ytterbium/Erbium-doped Double-Clad Optical Fibers" IEEE Transactions on Nuclear Sciences, vol. 56, nº, pp. 3293 - 3299, 2009.

[7] T.S. Rose, D. Gunn, G.C. Valley, "Gamma and proton radiation effect in erbium-doped amplifiers: active and passive measurements", J. Light. Technol., vol. 19, pp. 1918-1923, 2001.

[8] M. Li et al., Laser Physics, 19(1), pp.138-142, 2009

[9] A. Gusarov, M. Van Uffelen, M. Hotoleanu, H. Thienpont, and F. Berghmans, "Radiation Sensitivity of EDFAs Based on Highly Er-Doped Fibers", J. Light. Tech. 27(11), 1540-1545, 2009.

[10] M. Alam, J. Abramczyk, P. Madasamy, W. Torruellas, and A. Sanchez, "Fiber amplifier Performance in $\gamma$ radiation environment", OSA/Optical Fiber Conference 2007, paper OMF4.

[11] J. Ma, M. Li, L. Tan, Y. Zhou, S. Yu,Q. Ran, "Experimental investigation of radiation effect on erbiumytterbium co-doped fiber amplifier for space optical communication in low-dose radiation environment", Optic Express, vol.17, n¹8, pp. 15571-15579, 2009.

[12] S. Girard, A. Laurent, M. Vivona, C. Marcandella, T. Robin, B. Cadier, A. Boukenter, Y. Ouerdane, "Radiation effects on fiber amplifiers: design of radiation tolerant Er/Yb-based devices", in Proc. SPIE vol.7914, 79142P, 2011.

[13] Ixfiber SAS, http://www.ixfiber.com

[14]M. Vivona, S. Girard, C. Marcandella, T. Robin, B. Cadier, M. Cannas, A. Boukenter and Y. Ouerdane, "Influence of Ce codoping and $\mathrm{H} 2$ pre-loading on $\mathrm{Er} / \mathrm{Yb}$-doped fiber: Radiation response characterized by 
Confocal Micro-Luminescence", Journal of Non-Crystalline Solids, Volume 357, Issues 8-9, 15 April 2011, Pages 1963-1965.

[15] S. Girard, L. Mescia, M. Vivona, A. Laurent, Y. Ouerdane, C. Marcandella, F. Prundenzo, A. Boukenter, T. Robin, P. Paillet, V. Goiffon, B. Cadier, M. Cannas, and R. Boscaino, "Coupled Experiment/Simulation Approach for the Design of Radiation-Hardened Rare-Earth Doped Optical Fibers and Amplifiers", IEEE Transactions on Nuclear Science, submitted to, 2011. 